\title{
The proteome of pus from human brain abscesses: host-derived neurotoxic proteins and the cell-type diversity of CNS pus
}

\author{
Bjørnar Hassel, MD, PhD, ${ }^{1,2}$ Gustavo Antonio De Souza, PhD, ${ }^{3,4}$ Maria Ekman Stensland, PhD, ${ }^{3}$ \\ Jugoslav Ivanovic, MD, ${ }^{5}$ Øyvind Voie, PhD, ${ }^{2}$ and Daniel Dahlberg, MD ${ }^{5}$
}

\begin{abstract}
1Department of Complex Neurology and Neurohabilitation, ${ }^{3}$ nstitute of Immunology and Centre for Immune Regulation, and ${ }^{5}$ Department of Neurosurgery, Oslo University Hospital, University of Oslo; ${ }^{2}$ Norwegian Defence Research Establishment (FFI), Kjeller, Norway; and ${ }^{4}$ The Brain Institute, Universidade Federal do Rio Grande do Norte, Natal, Rio Grande do Norte, Brazil

OBJECTIVE What determines the extent of tissue destruction during brain abscess formation is not known. Pyogenic brain infections cause destruction of brain tissue that greatly exceeds the area occupied by microbes, as seen in experimental studies, pointing to cytotoxic factors other than microbes in pus. This study examined whether brain abscess pus contains cytotoxic proteins that might explain the extent of tissue destruction.
\end{abstract}

METHODS Pus proteins from 20 human brain abscesses and, for comparison, 7 subdural empyemas were analyzed by proteomics mass spectrometry. Tissue destruction was determined from brain abscess volumes as measured by MRI.

RESULTS Brain abscess volume correlated with extracellular pus levels of antibacterial proteins from neutrophils and macrophages: myeloperoxidase $(r=0.64)$, azurocidin $(r=0.61)$, lactotransferrin $(r=0.57)$, and cathelicidin $(r=0.52)(p$ values $0.002-0.018$ ), suggesting an association between leukocytic activity and tissue damage. In contrast, perfringoly$\sin 0$, a cytotoxic protein from Streptococcus intermedius that was detected in 16 patients, did not correlate with abscess volume $(r=0.12, p=0.66)$. The median number of proteins identified in each pus sample was 870 (range 643-1094). Antibiotic or steroid treatment prior to pus evacuation did not reduce the number or levels of pus proteins. Some of the identified proteins have well-known neurotoxic effects, e.g., eosinophil cationic protein and nonsecretory ribonuclease (also known as eosinophil-derived neurotoxin). The cellular response to brain infection was highly complex, as reflected by the presence of proteins that were specific for neutrophils, eosinophils, macrophages, platelets, fibroblasts, or mast cells in addition to plasma and erythrocytic proteins. Other proteins (neurofilaments, myelin basic protein, and glial fibrillary acidic protein) were specific for brain cells and reflected damage to neurons, oligodendrocytes, and astrocytes, respectively. Pus from subdural empyemas had significantly higher levels of plasma proteins and lower levels of leukocytic proteins than pus from intracerebral abscesses, suggesting greater turnover of the extracellular fluid of empyemas and washout of pus constituents.

CONCLUSIONS Brain abscess pus contains leukocytic proteins that are neurotoxic and likely participate actively in the excessive tissue destruction inherent in brain abscess formation. These findings underscore the importance of rapid evacuation of brain abscess pus. https://thejns.org/doi/abs/10.3171/2017.4.JNS17284

KEY WORDS brain abscess; eosinophil; macrophage; mast cell; neutrophil; subdural empyema; infection

$\mathrm{B}$ RAIN abscess formation implies tissue damage and the death of local brain cells, ${ }^{3,4}$ but what determines the extent of tissue destruction is not known. While the infecting microbes play a primary role in the formation of a brain abscess, it is a conundrum that the tissue destruction greatly exceeds the brain area occupied by bacteria, as has been seen in experimental studies..$^{15,20}$ This observation suggests that factors in addition to bacteria are important for the tissue damage. Analysis of pus (from dental infections) has identified hundreds of different pro-

ABBREVIATIONS FAM3C = family with sequence similarity 3C; GFAP = glial fibrillary acidic protein; MCEMP1 = mast cell-expressed membrane protein 1 ; MS = mass spectrometry.

SUBMITTED February 7, 2017. ACCEPTED April 14, 2017.

INCLUDE WHEN CITING Published online October 20, 2017; DOI: 10.3171/2017.4.JNS17284. 
teins. ${ }^{27}$ It is possible that pus contains neurotoxic proteins that could contribute to the cell death and neuronal dysfunction that accompanies brain abscess formation.

The purpose of the present study was 2-fold. First, we wished to identify pus proteins that could be neurotoxic and contribute to the cell death and tissue destruction inherent in brain abscess formation. To this end, we looked for correlations between abscess volume on the one hand and the concentration of various pus proteins on the other. Second, we wished to identify cell-specific proteins that could shed light on the types of cells that participate in the response to a pyogenic brain infection. We performed a proteomics analysis of the pus from 20 brain abscesses, both the extracellular phase of the pus (the supernatant obtained after centrifugation of the samples) and pus that had not been centrifuged and contained intact cells. Proteins in the extracellular phase of the pus were of special interest, because, being diffusible and not confined to an intracellular compartment, they could affect brain cells directly, causing toxicity, and they could diffuse into the brain tissue surrounding the abscess, causing symptoms that would not be explained by the lesion of the abscess itself. For comparison, we analyzed pus from 7 subdural empyemas, which, as reported in previous studies, appears to differ biochemically from intracerebral pus. ${ }^{7,8}$

\section{Methods}

\section{Patients and Samples}

Patients were recruited from 2012 to 2014 for this study, which was approved by the Regional Ethics Committee for Medical Research in the Southern and Eastern part of Norway. All consecutive patients with first-time brain abscesses or subdural empyemas who presented to the Department of Neurosurgery, Oslo University Hospital, were included. Patients who presented for repeat drainage of pus were not included. Informed written consent was obtained from all participants or their parents (in the case of children). All patients underwent 1.5-T MRI to determine pus localization, brain abscess volume, and abscess staging. ${ }^{4}$ Abscess volume was calculated using the ellipsoid formula: $4 / 3 \pi$ $\times r_{x} \times r_{y} \times r_{z}$. Pus from 20 patients with brain abscesses and 7 patients with subdural empyemas was collected at surgery by aspiration into polypropylene tubes that were immediately cooled on ice. After aspiration of the pus, the abscess cavity was rinsed with physiological saline, which was discarded. All samples were examined using light microscopy after May-Grünewald-Giemsa staining and were identified as pus because of the high content of neutrophils. All samples underwent conventional microbiological analysis, including culturing and polymerase chain reaction. A portion of each sample was centrifuged at $3000 \mathrm{~g}$ for 10 minutes at $4^{\circ} \mathrm{C}$ to obtain a supernatant. Supernatants and pus that had not been centrifuged were stored at $-70^{\circ} \mathrm{C}$ until analysis. The manner in which the pus was sampled made the sample representative of the entire abscess. The workflow is illustrated in Fig. 1.

\section{Sample Preparation}

Samples of pus from brain abscesses (supernatants or whole pus) or subdural empyemas (supernatants), $10 \mu \mathrm{l}$, were mixed with $200 \mu \mathrm{l}$ of $0.1 \%$ ProteaseMax buffer (Promega) dissolved in ammonium bicarbonate, $50 \mathrm{mmol} / \mathrm{L}$, $\mathrm{pH}$ 7.8. The protein concentration was measured on a Direct Detect infrared spectrometer (Millipore). A volume corresponding to $100 \mu \mathrm{g}$ of protein was in-solution digested in $0.2 \%$ ProteaseMAX according to manufacturer's instructions, using porcine trypsin (mass spectrometry [MS]-grade, sequence-modified, Promega), and samples were incubated at $37^{\circ} \mathrm{C}$ overnight. Porcine trypsin is detected as such in the proteomics analysis as described below. ProteaseMAX was degraded by adding trifluoroacetic acid to a final concentration of $0.5 \%$ ( $\mathrm{vol} / \mathrm{vol})$. Samples were left at room temperature for 5 minutes before the precipitate was removed by centrifugation at $14,000 \mathrm{~g}$ for 10 minutes. Before liquid chromatography (LC)-MS injection, the sample peptides were purified on $\mathrm{C} 18 \mathrm{mi}-$ crocolumns (Empore Extraction Disk, $3 \mathrm{M}$ ) as described. ${ }^{29}$

\section{Proteomics Analysis}

Protein separation and identification were done as described $^{19}$ on an EASY-nLC 1000 nano-LC system connected to a Quadrupole-Orbitrap (Q Exactive) MS (ThermoElectron) equipped with a nanoelectrospray ion source (EASY-Spray, Thermo).

\section{Protein Identification}

All MS raw files were submitted to MaxQuant software version 1.5.2.8 for protein identification. ${ }^{6}$ Parameters were set as previously described, ${ }^{19}$ including accepting protein $\mathrm{N}$-acetylation, methionine oxidation, and pyroglutamate conversion of glutamate and glutamine as variable modifications. We used a first search error window of $20 \mathrm{ppm}$ prior to mass recalibrations of acquired data, followed by a main search error window of $6 \mathrm{ppm}$ after mass recalibration. Trypsin without proline restriction enzyme option was used, with 2 allowed miscleavages. Minimum unique peptides were set to 1 , and the allowed false discovery rate was $1 \%$ for peptide spectrum matches and for peptide and protein identification. For the identification of bacterial proteins, a second MaxQuant search was performed, using the Oral Human Microbiome Database (downloaded October 2016, 1,120,000 entries; https://www.ncbi.nlm.nih.gov/pubmed/20624719), which identified 1 bacterial protein (https://www.ncbi.nlm.nih. gov/protein $/ 489168103$ ? report=genbank $\& \log \$=$ protalig n\&blast_rank=1\&RID=42Y0F22P015). The parameters were the same as for the Uniprot human database search, ${ }^{19}$ but, due to the larger size of the microbiome database and a higher chance of spurious identifications, the only bacterial proteins accepted as positive identifications in the samples were those with 3 or more identified peptides.

\section{Data Presentation and Statistical Analysis}

Data from the proteomics analysis are given as the logarithmic $(\log 10)$ transformations of the MS raw intensity data, which represent the area under the curve for the individual proteins. Data are given as mean values \pm SD. The mean and SD values were calculated only from samples in which the protein in question could be detected; the number of positive samples for each protein is given 

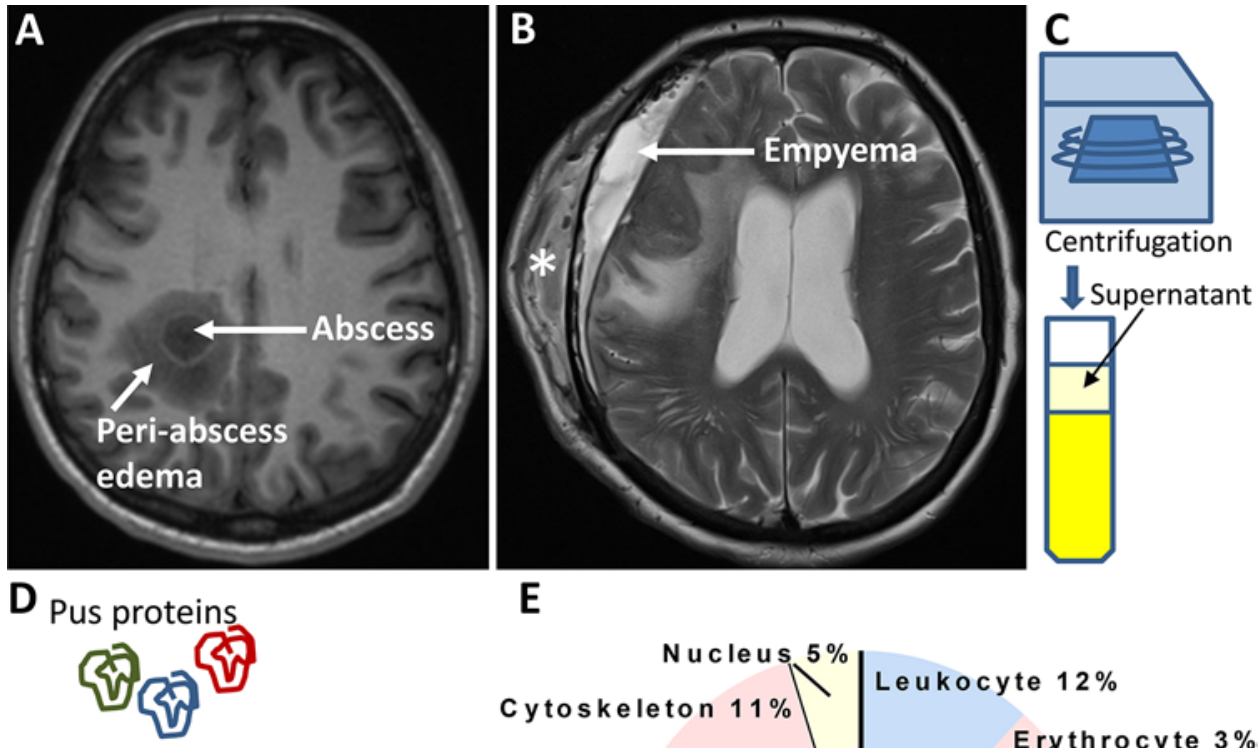

\section{E}

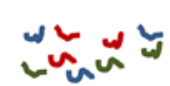

Trypsinization

Protein fragments

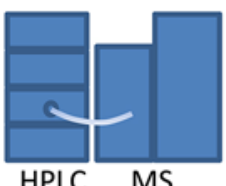

Separation

Ionization

Identification

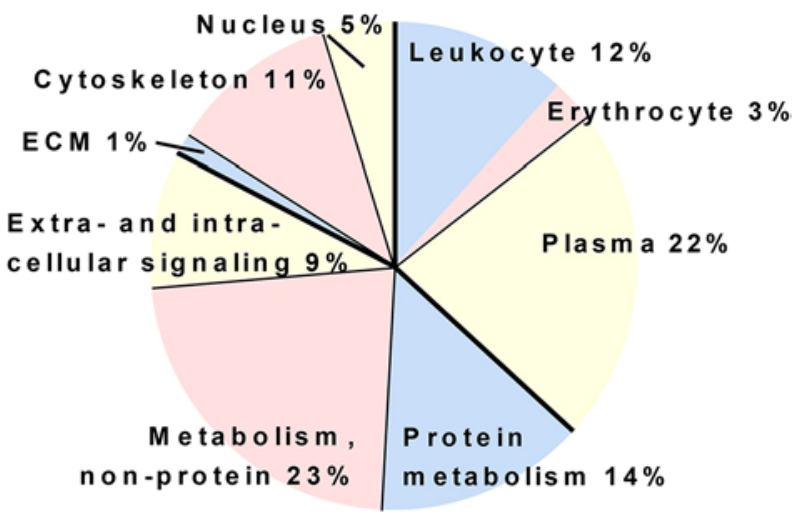

$\mathbf{F}$
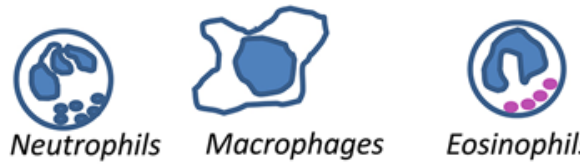

Eosinophils
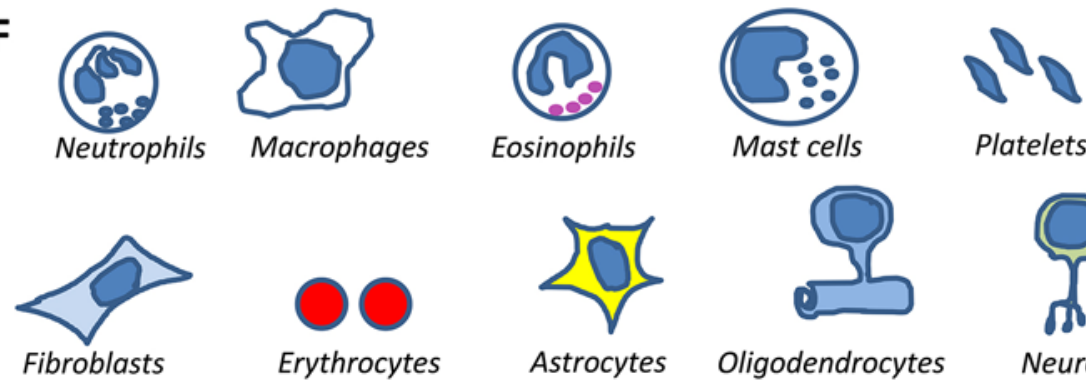

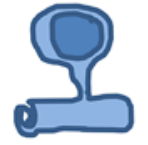

Oligodendrocytes
Platelets

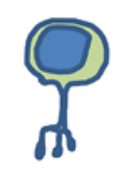

Neurons

FIG. 1. Outline of the workflow and results. A: Axial T1-weighted MR image of the brain obtained a patient with brain abscess, showing the abscess lying in the deep white matter of the parietal lobe with pronounced perilesional edema (arrows). B: Axial T2-weighted MRI of the brain obtained in a patient with subdural empyema after undergoing surgery for meningioma, showing the subdural pus (arrow) and swelling of soft tissue over the skull $\left({ }^{*}\right)$. C: During surgery, pus was harvested in polypropylene syringes and cooled on ice. A portion of the sample was centrifuged to obtain a supernatant, the extracellular phase of the pus. D: Proteins were trypsinized, and the protein fragments were separated by high-performance liquid chromatography (HPLC) and ionized and identified by MS using the MaxQuant program. ${ }^{9}$ E: Categorization of the 290 proteins identified in the extracellular fluid of all 20 brain abscesses according to origin (leukocyte, erythrocyte, and plasma), function (protein metabolism, non-protein metabolism, and extra- and intracellular signaling), or localization (extracellular matrix [ECM], cytoskeleton, and nucleus) in that order of priority. F: The various cell types identified from cell-specific proteins in brain abscess pus. Figure is available in color online only.

in the tables. Other data are given as median values and full ranges. For Fig. 1E, proteins were grouped according to origin (leukocyte, erythrocyte, plasma), function (intra- and extracellular signaling, protein metabolism, nonprotein metabolism), or localization (extracellular matrixrelated, cytoskeleton, nucleus) in that order of priority. For instance, an enzyme of known neutrophil origin would be classified according to origin rather than metabolic function or cellular localization.
Spearman's test (using GraphPad Prism) was used to determine correlations between the volume of the abscess or time from symptom onset to surgery on the one hand and protein levels, as detected by MS, on the other hand for the 290 proteins that were detected in the pus extracellular fluid of all 20 brain abscess samples. The sum of these 290 proteins was similar in the 20 samples, with standard deviation being only $3 \%$. Statistical comparison of protein abundance in the extracellular phase of brain 
abscesses and subdural empyemas was done after Z-score normalization of the data sets. The Student t-test was used for these tests and for evaluation of the effect of antibiotic or steroid treatment on pus protein values; $p$ values $<0.05$ were considered significant.

\section{Results}

\section{Patient Characteristics and Microbiology}

The 20 patients with brain abscesses ranged in age from 3 to 84 years (median age 58 years). There were 8 women and 12 men. The duration of symptoms prior to surgery ranged from 4 to 56 days (median 9 days). Abscess volumes ranged from 0.84 to $61 \mathrm{~cm}^{3}$. Abscesses were localized in any of the cerebral lobes; in 2 patients the abscess was localized in the cerebellum. Microbiological investigation of the pus revealed the presence of streptococci of the anginosus group (Streptococcus intermedius, Streptococcus constellatus, or Streptococcus anginosus) in 16 patients. In 5 of these patients, a mixed bacterial flora was found, including Prevotella oris, Parvimonas micra, and Porphyromonas endodontalis in one; Aggregatibacter aphrophilus in another; Fusobacterium nucleatum in a third; Actinomyces meyeri and P. micra in a fourth; and $P$. micra and $F$. naviforme in the remaining patient.

In one patient Aspergillus fumigatus and Aspergillus viridinutans were found; in another, Staphylococcus aureus; and in a third patient, Propionibacterium acnes together with $P$. micra and $F$. nucleatum. In the last patient A. aphrophilus, F. nucleatum, P. micra, and Actinomyces species were found. Proteomics analysis detected perfringolysin $\mathrm{O}$ from $S$. intermedius in 16 samples.

Most brain abscess patients had blood leukocyte counts above the reference range. The median value was $14.6 \times$ $10^{9}$ cells/ $\mathrm{L}$ (range 9.0-24.3 $\times 10^{9}$ cells $/ \mathrm{L}$; reference range 3.6-9.0 $\times 10^{9}$ cells/L); 1 patient had $6.9 \times 10^{9}$ cells/L, 2 had $9 \times 10^{9}$ cells/L, and the remaining patients had $>9 \times$ $10^{9}$ cells/L. The median C-reactive protein value in serum was $20 \mathrm{mg} / \mathrm{L}$ (range $0.6-200 \mathrm{mg} / \mathrm{L}$ ); in 4 patients the Creactive protein level was normal $(<4 \mathrm{mg} / \mathrm{L})$.

Eleven of the 20 patients received antibiotic treatment prior to abscess evacuation; 14 received steroids. Two patients received chemotherapy, a 65-year-old man with a brain lymphoma who developed a staphylococcal abscess after brain biopsy, and a 5-year-old boy with acute lymphatic leukemia who developed Aspergillus brain abscess.

The 7 patients with subdural empyemas were 45-78 years old (median age 71 years); 6 of these patients were men. The duration of symptoms prior to surgery ranged from 7 to 84 days (median 21 days). Four of the 7 empyemas occurred after surgery for a subdural hematoma, 2 after surgery for meningioma, and 1 occurred after frontal sinusitis. P. acnes was found in 4 patients, and S. aureus was found in 1 patient. In 2 patients a microbial identification was not achieved by culture or polymerase chain reaction, but proteomics analysis detected perfringolysin $\mathrm{O}$ from $\mathrm{S}$. intermedius.

In patients with subdural empyemas, the median blood leukocyte count was $8.1 \times 10^{9}$ cells/L (range 5.6-15.3 $\times 10^{9}$ cells/L); in 5 patients the value was normal (range 3.6-9.0 $\times 10^{9}$ cells $/ \mathrm{L}$ ). The $\mathrm{C}$-reactive protein level in serum was
$23 \mathrm{mg} / \mathrm{L}$ (range 1-278 mg/L); in 2 patients, the C-reactive protein level was normal $(<4 \mathrm{mg} / \mathrm{L})$. Two of the 7 patients received antibiotic treatment at the time of abscess surgery, and 1 received steroids.

\section{Categorization of the Proteins of the Extracellular Phase of Brain Abscesses}

The median number of proteins identified in each pus sample was 870 (range 643-1094). In total 1379 proteins were detected in at least one sample (Supplemental Table 1). The number of proteins that were detectable in all 20 brain abscess supernatants was 290 . The categorization of the 290 proteins according to cell type of origin, function, or subcellular localization is given in Fig. 1E. The cell types that could be inferred from the presence of cellspecific proteins as participating in the response to a pyogenic brain infection are illustrated in Fig. 1F.

Some proteins of the pus extracellular phase were of neutrophil or macrophage/microglial origin, such as several antibacterial proteins that were present in all 20 brain abscess samples: myeloperoxidase, lactotransferrin, myeloblastin, azurocidin, cathepsin G, bactericidal permeability-increasing protein, lysozyme $\mathrm{C}$, neutrophil elastase, cathelicidin, and neutrophil gelatinase-associated lipocalin, which inhibits iron uptake into bacteria ${ }^{14}$ (Table 1). Histones, which-together with myeloperoxidase, neutrophil elastase, and DNA-make up neutrophil extracellular traps that sequester microbes, ${ }^{2}$ were abundant in all samples. Peptide fragments that could represent beta amyloid, which has recently been assigned an antibacterial action, ${ }^{23}$ were detected in 7 samples; however, these fragments could also represent soluble amyloid precursor protein-alpha or -beta. Apolipoprotein B receptor, which is primarily expressed by macrophages, ${ }^{5}$ was detected in all 20 samples (Table 1).

Some eosinophil-derived granule proteins were abundant: nonsecretory ribonuclease (also known as eosinophil-derived neurotoxin), ${ }^{30}$ eosinophil cationic protein, and galectin-10 (Table 1).

In some samples, platelet-derived proteins were detected; platelet basic protein was detected in 12 samples, and platelet glycoprotein $\mathrm{Ib}$ was detected in 5 samples. Various collagen chains that are produced by fibroblasts ${ }^{4}$ were detected in a variable number of samples. Plasma and erythrocytic proteins were abundant, e.g., serum albumin, alpha-1-acid glycoprotein, fibrinogen, apolipoproteins, immunoglobulins, complement, and hemoglobin subunits.

A few proteins (neurofilaments, GFAP, and oligodendroglial proteins) could be ascribed to brain cells and probably reflected damage to brain tissue (Table 2).

Several cytokines and other proteins related to inflammation were detected (Table 3). Protein S100-A9 and protein S100-A8, key regulators of inflammation, ${ }^{28}$ were among the most abundant proteins in the pus extracellular fluid and were detected in all 20 samples, as were chitinase-3-like protein 1 (YKL-40), several 14-3-3 proteins, and resistin.

\section{Correlation Between Brain Abscess Volume and Protein Level}

Little is known about what determines the extent of tis- 
TABLE 1. A sample of leukocytic, plasma, and erythrocytic proteins as detected by MS in the extracellular phase of pus from brain abscesses and subdural empyemas

\begin{tabular}{|c|c|c|}
\hline Origin \& Protein & Abscess & Empyema \\
\hline \multicolumn{3}{|l|}{ Leukocytesł } \\
\hline Myeloperoxidase & $10.8 \pm 0.4^{* * *}$ & $9.6 \pm 0.7$ \\
\hline Histone H2B & $10.1 \pm 0.6$ & $9.6 \pm 0.8$ \\
\hline Myeloblastin (PR3) & $9.7 \pm 0.4^{* * *}$ & $8.7 \pm 0.6$ \\
\hline Matrix metalloproteinase-9 & $9.3 \pm 0.6^{* * *}$ & $8.5 \pm 1.1$ \\
\hline \multicolumn{3}{|l|}{ Neutrophils } \\
\hline Lactotransferrin (lactoferrin) & $10.5 \pm 0.3^{* * *}$ & $9.6 \pm 0.8$ \\
\hline $\begin{array}{l}\text { Neutrophil gelatinase-associated } \\
\text { lipocalin }\end{array}$ & $9.9 \pm 0.3^{* * *}$ & $8.9 \pm 0.5$ \\
\hline Leukocyte elastase inhibitor & $9.7 \pm 0.3^{* \star *}$ & $8.7 \pm 0.5$ \\
\hline Azurocidin (CAP37) & $9.5 \pm 0.4^{* * *}$ & $8.3 \pm 1.0$ \\
\hline Cathepsin G & $9.1 \pm 0.7^{* *}$ & $8.4 \pm 0.5$ \\
\hline $\begin{array}{l}\text { Bactericidal permeability-increasing } \\
\text { protein }\end{array}$ & $9.0 \pm 0.7^{\star \star}$ & $8.0 \pm 1.1$ \\
\hline Lysozyme C & $8.9 \pm 0.4^{* *}$ & $8.3 \pm 0.4$ \\
\hline Neutrophil elastase & $8.7 \pm 0.7^{*}$ & $7.8 \pm 1.0$ \\
\hline Cathelicidin (LL37) & $8.4 \pm 0.8$ & $8.3 \pm 0.7$ \\
\hline \multicolumn{3}{|l|}{ Eosinophils } \\
\hline Eosinophil cationic protein & $8.8 \pm 0.5$ & $8.4 \pm 0.6$ \\
\hline Nonsecretory ribonuclease & $8.8 \pm 0.6^{* *}$ & $7.6 \pm 0.6$ \\
\hline Galectin-10 & $8.2 \pm 0.6$ & $7.6 \pm 0.5$ \\
\hline \multicolumn{3}{|l|}{ Macrophage } \\
\hline Apolipoprotein B receptor & $7.6 \pm 0.5$ & $7.8 \pm 0.6$ \\
\hline \multicolumn{3}{|l|}{ Plasma } \\
\hline Serum albumin & $11.4 \pm 0.4$ & $11.9 \pm 0.1$ \\
\hline Fibrinogen beta chain & $10.4 \pm 0.3 \dagger$ & $10.7 \pm 0.2$ \\
\hline Alpha-1-acid glycoprotein 2 & $10.0 \pm 0.5 \dagger \dagger \dagger$ & $10.8 \pm 0.2$ \\
\hline Complement C3 & $9.3 \pm 0.7 \dagger \dagger \dagger$ & $10.6 \pm 0.3$ \\
\hline Fibrinogen alpha chain & $9.3 \pm 0.6 \dagger \dagger$ & $9.7 \pm 0.3$ \\
\hline Antithrombin-III & $9.1 \pm 0.4 \uparrow \uparrow \dagger$ & $10.1 \pm 0.2$ \\
\hline Fibronectin & $9.1 \pm 0.6 \dagger \dagger$ & $10.4 \pm 0.4$ \\
\hline Ig gamma-3 chain $\mathrm{C}$ region & $8.7 \pm 0.3 † \dagger \dagger$ & $9.5 \pm 0.1$ \\
\hline Alpha-1-antichymotrypsin & $8.5 \pm 0.5 \dagger \uparrow \dagger$ & $10.2 \pm 0.5$ \\
\hline Alpha-2-antiplasmin & $8.5 \pm 0.4 \uparrow \uparrow \uparrow$ & $9.5 \pm 0.4$ \\
\hline Apolipoprotein A-II & $7.8 \pm 0.9 \dagger \dagger$ & $9.8 \pm 0.4$ \\
\hline Complement factor I & $7.7 \pm 0.5 \dagger \dagger$ & $9.1 \pm 0.4$ \\
\hline Alpha-2-HS-glycoprotein & $7.7 \pm 0.8 \dagger \dagger$ & $9.8 \pm 0.1$ \\
\hline \multicolumn{3}{|l|}{ Erythrocytes } \\
\hline Hemoglobin subunit A & $11.5 \pm 0.4$ & $11.2 \pm 0.5$ \\
\hline Hemoglobin subunit B & $11.4 \pm 0.3$ & $11.4 \pm 0.4$ \\
\hline
\end{tabular}

In total, 290 proteins were present in the extracellular phase of all 20 brain abscesses (intracerebral) and all 7 empyemas (extracerebral). Thirty-two of the 41 most abundant proteins are shown here. Proteins are grouped according to their origin (cellular or plasma) in decreasing order of abundance. Data are log10 values of the raw MS intensity data (and therefore without units), mean \pm SD. Statistical analysis was done using the Student t-test after Z-score normalization. * Indicates that the abscess values are higher than the empyema values: ${ }^{*} p<$ $0.05 ;{ }^{* *} p<0.01 ;{ }^{* * *} p<0.001$

$\dagger$ Indicates that the abscess values are lower than the empyema values: $\uparrow p<$ $0.05 ; \uparrow \uparrow p<0.01$; and $\uparrow \nmid p<0.001$.

$\ddagger$ Refers to neutrophils and macrophages/microglia, but values mostly reflect neutrophils, which dominate pus. ${ }^{25}$
TABLE 2. Brain-specific proteins in the extracellular phase of brain abscess pus

\begin{tabular}{lcc}
\hline \multicolumn{1}{c}{ Origin \& Protein } & Abundance* & $\begin{array}{c}\text { No. of Positive } \\
\text { Samples }\end{array}$ \\
\hline Neurons & & \\
\hline Neurofilament light polypeptide & $7.5 \pm 0.8$ & 14 \\
\hline Neurofilament medium polypeptide & $7.4 \pm 0.7$ & 13 \\
\hline Neurofilament heavy polypeptide & $6.0,6.4$ & 2 \\
\hline Oligodendrocytes & & \\
\hline$\quad$ Myelin proteolipid protein & $8.3 \pm 0.9$ & 11 \\
\hline $\begin{array}{l}\text { 2,3-cyclic-nucleotide 3-phosphodi- } \\
\text { esterase }\end{array}$ & $8.1 \pm 0.8$ & 17 \\
\hline Myelin P2 protein & $7.1 \pm 0.6$ & 6 \\
\hline Myelin basic protein & $6.8 \pm 1.0$ & 13 \\
\hline Oligodendrocyte-myelin glycoprotein & $6.7,6.8$ & 2 \\
\hline Astrocyte & & \\
\hline GFAP & $8.3 \pm 0.9$ & 20 \\
\hline
\end{tabular}

Pus from 20 brain abscesses was centrifuged, and the supernatant proteome was analyzed by MS. Data are $\log 10$ values of the raw MS intensity data, mean \pm SD.

* Calculated from the values of the positive samples.

sue damage in a pyogenic brain infection. As an approach to this question, we looked for correlations between abscess volume, as determined from MR images, and levels of the 290 proteins that could be detected in all 20 samples of pus extracellular fluid. The level of 57 extracellular pus proteins correlated with the volume of the abscesses $(\mathrm{r}=$ 0.44-0.78; $\mathrm{p}<0.001-0.049$; Supplemental Table 2). Table 4 shows some proteins with correlation coefficients $>0.5$. Ten proteins, including myeloperoxidase, aminopeptidase $\mathrm{N}$, azurocidin, lactotransferrin, cathelicidin, cathepsin $\mathrm{G}$, neutrophil collagenase, and resistin could be ascribed to neutrophils or macrophages. Thirty proteins (only some of which are shown in Table 4), could be classified as plasma proteins, including serum albumin, immunoglobulins, and complement factors. Seventeen proteins (e.g., $\beta$-glucuronidase and histone H4) could not be ascribed to a specific cell type. Erythrocytic proteins did not correlate with abscess volume, nor did perfringolysin $\mathrm{O}$ from $S$. intermedius in the 16 samples in which it was detected $(\mathrm{r}=0.12$; $\mathrm{p}=0.66$ ).

The serum protein $\alpha$-1-antichymotrypsin correlated positively with time from symptom onset to surgery $(\mathrm{r}=$ $0.48 ; \mathrm{p}=0.03$ ). Leukocytic proteins galectin-10 and lysozyme $\mathrm{C}$ correlated negatively with time from symptom onset to surgery (both: $r=-0.47 ; p=0.03$ ), possibly reflecting a modulation of the inflammatory response with time. There was no significant correlation between the number of identified proteins or the total protein levels in the pus samples on the one hand and time from symptom onset to surgery ( $r=-0.08$ to $-0.5, p>0.7)$. Abscess staging was highly correlated with time from symptom onset to surgery $\left(r=0.72, p=3 \times 10^{-4}\right.$; Spearman's test). However, abscess stage did not correlate with the total number of proteins detected, the total level of proteins in pus extracellular fluid, or with the level of any specific protein. 
TABLE 3. Cytokines and other proteins of inflammation in the extracellular fluid of brain abscesses and empyemas, as detected by MS

\begin{tabular}{lccccc}
\hline & \multicolumn{2}{c}{ Abscess $(\mathrm{n}=20)$} & & \multicolumn{2}{c}{ Empyema $(\mathrm{n}=7)$} \\
\cline { 2 - 3 } \cline { 5 - 6 } \multicolumn{1}{c}{ Protein } & Abundance & No. of Positive Samples & & Abundance & No. of Positive Samples \\
\hline Protein S100-A9 & $11.5 \pm 0.3^{* * *}$ & 20 & $10.8 \pm 0.5$ & 7 \\
\hline Protein S100-A8 & $10.8 \pm 0.2^{* * *}$ & 20 & $10.2 \pm 0.5$ & 7 \\
\hline Protein 14-3-3 zeta/delta & $9.5 \pm 0.5$ & 20 & $9.1 \pm 0.7$ & 7 \\
\hline Protein 14-3-3 epsilon & $8.8 \pm 0.4$ & 20 & $8.4 \pm 0.5$ & 7 \\
\hline Protein 14-3-3 alpha/beta & $8.4 \pm 0.7$ & 20 & $8.2 \pm 0.7$ & 7 \\
\hline Chitinase-3-like protein 1 (YKL-40) & $8.9 \pm 0.6$ & 20 & $8.1 \pm 0.6$ & \\
\hline Resistin & $8.7 \pm 0.5^{* *}$ & 20 & $7.7 \pm 0.6$ & \\
\hline Macrophage migration inhibitory factor & $8.5 \pm 0.6$ & 19 & $7.9 \pm 0.3$ & 7 \\
\hline Glia maturation factor gamma & $7.5 \pm 0.4$ & 14 & $7.5 \pm 0.5$ & 6 \\
\hline Platelet basic protein & $7.2 \pm 0.7$ & 12 & $7.3 \pm 0.7$ & 5 \\
\hline Interleukin-16 & $5.9 \pm 0.7$ & 4 & 6.0 & 5 \\
\hline
\end{tabular}

Data are MS intensity values logarithmically transformed $(\log 10)$, mean $\pm S D$, as calculated from the positive samples.

* Indicates that the abscess values are higher than empyema values. ${ }^{* *} p<0.01 ;{ }^{* * *} p<0.001$. Statistical analysis was performed using the Student $t$-test after Z-score normalization.

Three patients required a second pus evacuation procedure; the numbers of proteins identified in the pus or their levels did not differ from those in the other patients.

\section{Correlation Between Brain Abscess Proteins and Systemic Signs of Infection}

The level of C-reactive protein in serum correlated negatively with the number of proteins that could be detected in each pus sample $(r=-0.49, p=0.029)$ and with the total amount of protein in each sample $(\mathrm{r}=-0.45, \mathrm{p}=$ 0.049 ), possibly suggesting that the fewer pus proteins that escape from the abscess cavity, the weaker is the systemic reaction to a brain infection. Only a few individual protein levels correlated (negatively) with the level of C-reactive protein in serum: aminopeptidase $\mathrm{N}(\mathrm{r}=-0.46, \mathrm{p}=0.022)$, nonsecretory ribonuclease $(\mathrm{r}=-0.50, \mathrm{p}=0.023), \alpha$-anti chymotrypsin $(\mathrm{r}=-0.51, \mathrm{p}=0.021)$, and cathelicidin $(\mathrm{r}=$ $-0.49, \mathrm{p}=0.028)$. Only the level of lactotransferrin correlated positively with C-reactive protein levels $(r=0.46, p$ $=0.039)$. The blood leukocyte count did not correlate with protein numbers or levels, possibly illustrating a differential response of liver and bone marrow to a focal brain infection.

There was no significant difference in the number or levels of pus proteins between the 11 patients who had received antibiotic treatment prior to surgery and the 9 who had not. The patients who had received antibiotics had a median of 895 proteins (range 671-1089), and those who had not been treated had a median 817 proteins (range 640-949; $\mathrm{p}=0.23$ ). There was also no significant difference between the 14 patients who had received steroid treatment prior to surgery and the 6 who had not $(890$ proteins, range 638-1089; vs 822, range 640-906; $p=$ 0.58). The 2 patients who received chemotherapy did not stand out with respect to pus protein levels; in particular, the numbers or levels of proteins in the pus extracellular phase in the patient with a fungal brain abscess did not differ from those in the 19 patients with bacterial brain abscesses. There was no difference with respect to the num- ber of identified proteins or their levels between the 7 pus samples with multiple microbial isolates and the 13 with only one identified pathogen (data not shown).

\section{The Proteome of Cell-Rich Brain Abscess Pus}

In pus that had not been centrifuged and therefore had intact cells, 1570 proteins were detected in at least one of the 20 samples. Of these, 436 proteins were unique to cellrich pus and were not found in cell-free supernatants (Supplemental Table 3). Of the 436 proteins, 41 were detected in all 20 cell-rich samples. The most abundant of these, as detected by MS, was FAM3C (family with sequence similarity $3 \mathrm{C}$ ), which has a role in cancer biology, ${ }^{22}$ but which has so far not been associated with infection. The MCEMP1 (mast cell-expressed membrane protein 1) was detected in 3 samples.

\section{The Proteome of Subdural Empyemas}

The median number of extracellular proteins identified per empyema sample was 839 (range 623-933). The number of proteins that were detected in all 7 empyema supernatants was $416 ; 1128$ proteins were detected in at least one sample (Supplemental Table 4).

A total of 214 proteins were detected in the extracellular fluid of all 7 empyemas and all 20 brain abscesses. Proteins originating from plasma (e.g., apolipoproteins, immunoglobulins, and fibrinogen) were significantly more abundant in subdural empyemas than in brain abscess pus (Table 1; see Supplemental Table 5 for full data set). In contrast, leukocytic proteins (e.g., myeloperoxidase, myeloblastin, and lactotransferrin) were significantly more abundant in brain abscesses than in empyemas.

\section{Discussion}

\section{Brain Abscess Pus Contains Neurotoxic Proteins}

We show here that brain abscess volume correlated with the levels of several antibacterial proteins from leukocytes 
TABLE 4. Correlation between abscess volume and protein level in the extracellular fluid of brain abscess pus*

\begin{tabular}{|c|c|c|c|c|}
\hline Protein & Origin & $r$ & $95 \% \mathrm{Cl}$ & $\begin{array}{c}p \\
\text { Value }\end{array}$ \\
\hline $\lg \lambda$ chain $V$-III region SH & Serum & 0.78 & $0.50-0.91$ & $<0.001$ \\
\hline$\alpha$-2-macroglobulin & Serum & 0.71 & $0.37-0.88$ & $<0.001$ \\
\hline$\alpha$-1B-glycoprotein & Serum & 0.70 & $0.37-0.88$ & $<0.001$ \\
\hline Aminopeptidase $\mathrm{N}$ & Nonspecific $†$ & 0.70 & $0.36-0.88$ & $<0.001$ \\
\hline$\alpha-1$-acid glycoprotein 1 & Serum & 0.69 & $0.35-0.87$ & $<0.001$ \\
\hline Corticosteroid-BG & Serum & 0.67 & $0.31-0.86$ & 0.001 \\
\hline Myeloperoxidase & Leukocytesł & 0.64 & $0.26-0.85$ & 0.002 \\
\hline Ceruloplasmin & Serum & 0.63 & $0.24-0.84$ & 0.003 \\
\hline$\alpha$-1-acid glycoprotein 2 & Serum & 0.63 & $0.24-0.84$ & 0.003 \\
\hline$\beta$-glucuronidase & Nonspecific & 0.62 & $0.23-0.84$ & 0.004 \\
\hline Azurocidin & Neutrophils & 0.61 & $0.21-0.83$ & 0.005 \\
\hline Complement C4-B & Serum & 0.60 & $0.19-0.83$ & 0.006 \\
\hline Lactotransferrin & Neutrophils & 0.57 & $0.16-0.81$ & 0.008 \\
\hline Histone H4 & Nonspecific & 0.56 & $0.14-0.81$ & 0.011 \\
\hline Cathelicidin & Neutrophils & 0.52 & $0.09-0.79$ & 0.018 \\
\hline Resistin & Neutrophils & 0.51 & $0.07-0.78$ & 0.022 \\
\hline
\end{tabular}

Corticosteroid-BG = corticosteroid-binding globulin.

* As detected by MS for the 12 proteins with $r \geq 0.60$ (for the full data set for 57 proteins, see Supplemental Table 2). Spearman's test was used.

$\dagger$ Aminopeptidase $\mathrm{N}$ probably originated largely from the plasma membrane of neutrophils. ${ }^{13}$

$\ddagger$ Refers to neutrophils and macrophages/microglia, but myeloperoxidase probably originated mostly from neutrophils, which dominate pus. ${ }^{25}$

(neutrophils and macrophages/microglia) in the pus, suggesting a causal relationship between the activity of these cell types and damage to brain tissue. This correlation was seen for myeloperoxidase, azurocidin, cathelicidin, and lactotransferrin among others. Myeloperoxidase, through its product hypochlorite, has been implicated in neurodegenerative states of the brain and in the tissue damage following stroke, ${ }^{31}$ as has azurocidin. ${ }^{36}$ Cathelicidin has been shown to both worsen ${ }^{24}$ and ameliorate ${ }^{9}$ neuroinflammation. In contrast, lactotransferrin may have a neuroprotective effect. ${ }^{38}$

Several other proteins could contribute to tissue damage. The eosinophil-derived proteins eosinophil cationic protein and nonsecretory ribonuclease (also known as eosinophil-derived neurotoxin), which were detected in the extracellular phase of all 20 brain abscesses, have wellknown neurotoxic effects. The former has been shown to cause apoptosis of both neurons and glial cells in vitro; ${ }^{26}$ the latter produces Purkinje cell death and white matter damage in experimental animals on intracerebral injection. ${ }^{10}$

The proteases neutrophil elastase and matrix metalloproteinase- 9 , which were abundant in brain abscess pus, have been shown to damage brain extracellular proteins, affecting synaptic integrity ${ }^{11}$ as well as the blood-brain barrier. ${ }^{1,32,37}$ Damage to extracellular proteins could probably be done even by other proteases of the pus extracellular fluid.

The level of several plasma proteins correlated strongly with abscess volume. We cannot at present say whether these correlations reflect a neurotoxic effect of plasma proteins per se, or whether they reflect the leakiness of the blood-brain barrier as an effect of inflammation, that is, a greater degree of inflammation leading to greater influx of serum proteins into the abscess cavity. However, serum albumin has been shown to have a neurotoxic potential, ${ }^{12,16}$ and this could be true for many pus proteins whose cytotoxic potential has not yet been investigated.

\section{The Pus Proteome Reflects the Cell Types That Take Part in Abscess Formation}

An impressive array of cells takes part in the response to a pyogenic brain infection, as illustrated by the cell-specific proteins of the pus. Proteins from neutrophils and macrophages/microglia were abundant, in agreement with their well-known role in bacterial infections. ${ }^{25,34}$ However, eosinophil-specific proteins (eosinophil cationic protein, nonsecretory ribonuclease) were also abundant, suggesting an important role for eosinophils in the antibacterial response to brain infection. A role for eosinophils in bacterial infections has become increasingly clear, including chemokine secretion, phagocytosis, and release of antibacterial proteins. ${ }^{30}$ The presence of mast cell protein MCEMP1 in brain abscess pus was unexpected, as mast cells tend to reside in tissues that are exposed to the environment (e.g., skin, gut, airway) ${ }^{17}$ however, the role of mast cells in bacterial infections includes release of chemokines, antigen presentation, and possibly phagocytosis. ${ }^{17}$ The presence of platelet-specific proteins suggests a role for platelets in focal brain infections. Platelets have a well-known role in hemostasis but are increasingly being recognized as players in innate immune responses to infection, interacting with neutrophils in limiting microbial spread, and taking part in the regulation of innate immune responses through release of cytokines and chemokines,,$^{18}$ e.g., platelet basic protein, which was detected in the present study.

\section{Extracerebral and Intracerebral Pus: Difference in Turnover of the Extracellular Fluid}

The extracellular phase of pus from subdural (extracerebral) empyemas had higher levels of several plasma proteins than did (intracerebral) brain abscesses. This difference probably reflects the localization of empyemas outside the blood-brain barrier. This location readily allows influx of plasma proteins into the pus area, and it probably allows for greater turnover of the extracellular fluid of the pus and greater washout of pus constituents. In agreement with this assumption, we found lower concentrations of leukocytic proteins in empyema pus, which is in line with our previous finding that the extracellular concentration of amino acids and ammonia in empyemas is $\leq 10 \%$ of that found in brain abscess pus.,8

\section{Limitations of the Study: Perspectives}

We conclude that the pus proteome seems to be unaffected by antibiotic or steroid treatment or by the type of infecting organism(s). While this conclusion seems reasonable in the present study on a limited sample size, future studies on larger sample sizes may uncover important in- 
teractions between invading microbes, medical treatment, and the host response.

A cytotoxic effect of leukocytes is assumed in other disease states of the CNS, such as in neuroinflammation ${ }^{32}$ and trauma, ${ }^{33}$ and it is known from bacterial infections in other tissues where abscesses are formed, such as skin. ${ }^{21}$ Tissue destruction during abscess formation (e.g., in the skin) is beneficial if it causes the abscess to rupture to the surface of the body so that pus and bacteria are expelled. In the case of an infection in the brain, however, the skull does not allow the abscess to rupture to the body surface. Thus, the tissue destruction due to abscess formation in the brain is probably only disadvantageous. On this basis, one may envisage future brain abscess therapy directed against the neurotoxic effect of leukocytic proteins in addition to drainage of pus and antibiotic treatment. Although we have identified a number of leukocytic proteins whose level in pus correlates with degree of tissue destruction, we have not identified the mechanisms of cell death that these proteins activate. Further studies are needed to identify cell death mechanisms and molecular targets for therapies directed at limiting the tissue destruction inherent in pyogenic brain infections.

We provide data that suggest that the degree of leukocytic activity underlies the extent of tissue destruction during brain abscess formation; however, we lack data on what determines the degree of leukocytic activity. Virulence factors of the infecting microbes may be of importance; however, idiosyncrasies of the innate immune response or of the brain tissue of the individual patient may also be important. These factors are topics for future studies.

\section{Conclusions}

Studies on experimental bacterial brain infections have shown that the area of tissue damage greatly exceeds the area occupied by bacteria, ${ }^{15,20}$ pointing to neurotoxic factors other than bacteria in brain abscess pus. We conclude that leukocytic antibacterial proteins, which have known neurotoxic effects, likely contribute actively to the tissue destruction inherent in brain abscess formation. This conclusion underscores the importance of rapid evacuation of brain abscesses, ${ }^{35}$ because leukocytic proteins may cause brain damage even after antibiotic treatment is begun.

\section{Acknowledgments}

This study was supported by The Norwegian Epilepsy Association (NEF) and Reberg's legat.

\section{References}

1. Armao D, Kornfeld M, Estrada EY, Grossetete M, Rosenberg GA: Neutral proteases and disruption of the blood-brain barrier in rat. Brain Res 767:259-264, 1997

2. Brinkmann V, Zychlinsky A: Neutrophil extracellular traps: is immunity the second function of chromatin? J Cell Biol 198:773-783, 2012

3. Britt RH, Enzmann DR, Yeager AS: Neuropathological and computerized tomographic findings in experimental brain abscess. J Neurosurg 55:590-603, 1981

4. Britt RH, Enzmann DR: Clinical stages of human brain abscesses on serial CT scans after contrast infusion. Comput- erized tomographic, neuropathological, and clinical correlations. J Neurosurg 59:972-989, 1983

5. Brown ML, Ramprasad MP, Umeda PK, Tanaka A, Kobayashi Y, Watanabe T, et al: A macrophage receptor for apolipoprotein B48: cloning, expression, and atherosclerosis. Proc Natl Acad Sci U S A 97:7488-7493, 2000

6. Cox J, Mann M: MaxQuant enables high peptide identification rates, individualized p.p.b.-range mass accuracies and proteome-wide protein quantification. Nat Biotechnol 26:1367-1372, 2008

7. Dahlberg D, Ivanovic J, Hassel B: High extracellular concentration of excitatory amino acids glutamate and aspartate in human brain abscess. Neurochem Int 69:41-47, 2014

8. Dahlberg D, Ivanovic J, Hassel B: Toxic levels of ammonia in human brain abscess. J Neurosurg 124:854-860, 2016

9. Dörr A, Kress E, Podschun R, Pufe T, Tauber SC, Brandenburg LO: Intrathecal application of the antimicrobial peptide CRAMP reduced mortality and neuroinflammation in an experimental model of pneumococcal meningitis. J Infect 71:188-199, 2015

10. Durack DT, Ackerman SJ, Loegering DA, Gleich GJ: Purification of human eosinophil-derived neurotoxin. Proc Natl Acad Sci U S A 78:5165-5169, 1981

11. Dziembowska M, Wlodarczyk J: MMP9: a novel function in synaptic plasticity. Int J Biochem Cell Biol 44:709-713, 2012

12. Eimerl S, Schramm M: Acute glutamate toxicity in cultured cerebellar granule cells: agonist potency, effects of $\mathrm{pH}, \mathrm{Zn}^{2+}$ and the potentiation by serum albumin. Brain Res 560:282290, 1991

13. Fiddler CA, Parfrey H, Cowburn AS, Luo D, Nash GB, Murphy G, et al: The aminopeptidase CD13 induces homotypic aggregation in neutrophils and impairs collagen invasion. PLoS One 11:e0160108, 2016

14. Flo TH, Smith KD, Sato S, Rodriguez DJ, Holmes MA, Strong RK, et al: Lipocalin 2 mediates an innate immune response to bacterial infection by sequestrating iron. Nature 432:917-921, 2004

15. Hassel B, Dahlberg D, Mariussen E, Goverud IL, Antal EA, Tønjum T, et al: Brain infection with Staphylococcus aureus leads to high extracellular levels of glutamate, aspartate, $\gamma$ aminobutyric acid, and zinc. J Neurosci Res 92:1792-1800, 2014

16. Hassel B, Iversen EG, Fonnum F: Neurotoxicity of albumin in vivo. Neurosci Lett 167:29-32, 1994

17. Johnzon CF, Rönnberg E, Pejler G: The role of mast cells in bacterial infection. Am J Pathol 186:4-14, 2016

18. Kapur R, Semple JW: The nonhemostatic immune functions of platelets. Semin Hematol 53 (1 Suppl 1):S2-S6, 2016

19. Karlsen TA, de Souza GA, Ødegaard B, Engebretsen L, Brinchmann JE: microRNA-140 inhibits inflammation and stimulates chondrogenesis in a model of interleukin $1 \beta$-induced osteoarthritis. Mol Ther Nucleic Acids 5:e373, 2016

20. Kielian T: Immunopathogenesis of brain abscess. J Neuroinflammation 1:16, 2004

21. Kobayashi SD, Malachowa N, DeLeo FR: Pathogenesis of Staphylococcus aureus abscesses. Am J Pathol 185:15181527,2015

22. Kraya AA, Piao S, Xu X, Zhang G, Herlyn M, Gimotty P, et al: Identification of secreted proteins that reflect autophagy dynamics within tumor cells. Autophagy 11:60-74, 2015

23. Kumar DK, Choi SH, Washicosky KJ, Eimer WA, Tucker $S$, Ghofrani J, et al: Amyloid- $\beta$ peptide protects against microbial infection in mouse and worm models of Alzheimer's disease. Sci Transl Med 8:340ra72, 2016

24. Lee M, Shi X, Barron AE, McGeer E, McGeer PL: Human antimicrobial peptide LL-37 induces glial-mediated neuroinflammation. Biochem Pharmacol 94:130-141, 2015

25. Malech HL, Deleo FR, Quinn MT: The role of neutrophils 
in the immune system: an overview. Methods Mol Biol 1124:3-10, 2014

26. Navarro S, Boix E, Cuchillo CM, Nogués MV: Eosinophilinduced neurotoxicity: the role of eosinophil cationic protein/ RNase 3. J Neuroimmunol 227:60-70, 2010

27. Provenzano JC, Siqueira JF Jr, Rôças IN, Domingues RR, Paes Leme AF, Silva MR: Metaproteome analysis of endodontic infections in association with different clinical conditions. PLoS One 8:e76108, 2013

28. Pruenster M, Vogl T, Roth J, Sperandio M: S100A8/A9: From basic science to clinical application. Pharmacol Ther 167:120-131, 2016

29. Rappsilber J, Ishihama Y, Mann M: Stop and go extraction tips for matrix-assisted laser desorption/ionization, nanoelectrospray, and LC/MS sample pretreatment in proteomics. Anal Chem 75:663-670, 2003

30. Ravin KA, Loy M: The eosinophil in infection. Clin Rev Allergy Immunol 50:214-227, 2016

31. Ray RS, Katyal A: Myeloperoxidase: bridging the gap in neurodegeneration. Neurosci Biobehav Rev 68:611-620, 2016

32. Saadoun S, Waters P, MacDonald C, Bell BA, Vincent A, Verkman AS, et al: Neutrophil protease inhibition reduces neuromyelitis optica-immunoglobulin G-induced damage in mouse brain. Ann Neurol 71:323-333, 2012

33. Schwartz M: Macrophages and microglia in central nervous system injury: are they helpful or harmful? J Cereb Blood Flow Metab 23:385-394, 2003

34. Silva MT: When two is better than one: macrophages and neutrophils work in concert in innate immunity as complementary and cooperative partners of a myeloid phagocyte system. J Leukoc Biol 87:93-106, 2010

35. Smith SJ, Ughratdar I, MacArthur DC: Never go to sleep on undrained pus: a retrospective review of surgery for intraparenchymal cerebral abscess. Br J Neurosurg 23:412-417, 2009

36. Stock AJ, Kasus-Jacobi A, Wren JD, Sjoelund VH, Prestwich GD, Pereira HA: The role of neutrophil proteins on the amyloid beta-RAGE axis. PLoS One 11:e0163330, 2016
37. Turner RJ, Sharp FR: Implications of MMP9 for blood brain barrier disruption and hemorrhagic transformation following ischemic stroke. Front Cell Neurosci 10:56, 2016

38. Wang J, Bi M, Liu H, Song N, Xie J: The protective effect of lactoferrin on ventral mesencephalon neurons against MPP + is not connected with its iron binding ability. Sci Rep 5:10729, 2015

\section{Disclosures}

The authors report no conflict of interest concerning the materials or methods used in this study or the findings specified in this paper.

\section{Author Contributions}

Conception and design: Hassel, Dahlberg. Acquisition of data: De Souza, Stensland, Ivanovic, Dahlberg. Analysis and interpretation of data: Hassel, De Souza, Stensland, Voie, Dahlberg. Drafting the article: Hassel, De Souza, Voie, Dahlberg. Critically revising the article: Hassel, Stensland, Ivanovic, Voie, Dahlberg. Reviewed submitted version of manuscript: all authors. Statistical analysis: Hassel, De Souza, Voie. Study supervision: Hassel.

\section{Supplemental Information}

\section{Online-Only Content}

Supplemental material is available with the online version of the article.

Supplemental Tables. https://thejns.org/doi/suppl/10.3171/2017. 4.JNS17284.

\section{Correspondence}

Bjørnar Hassel, Department of Complex Neurology and Neurohabilitation, Oslo University Hospital, Kirkevn. 166, Oslo 0450, Norway.email: bjornar.hassel@medisin.uio.no. 